\title{
LA SEGURIDAD NACIONAL Y LA EXCEPCIÓN EN EL SISTEMA EUROPEO COMÚN DE ASILO (SECA).
}

JORGE AGUSTIIN VIGURI CORDERO 


\section{SUMARIO}

1. Introducción. 2. Los problemas relativos a seguridad y su alcance en el actual sistema europeo común de asilo (SECA). 2.1. El impacto de la seguridad nacional en el actual seca. 2.2. Desmitificando la actual correlación entre asilo y terrorismo. 3. La seguridad en la propuesta del SECA: claves de la nueva reforma. 4. La radicalización como excepción al parámetro de evaluación de la seguridad en el seca. 4.1. Retos emergentes de la radicalización y reclutamiento en el ámbito de la protección internacional. 4.2. La radicalización en línea como forma de lucha contra el terrorismo: un emergente conflicto constitucional asilo vs. Seguridad. 5. Conclusiones. 


\title{
LA SEGURIDAD NACIONAL Y LA EXCEPCIÓN EN EL SISTEMA EUROPEO COMÚN DE ASILO (SECA).
}

\author{
JORGE AGUSTÍN VIGURI CORDERO ${ }^{1}$ \\ Investigador de la Universitat Jaume I (UJI)
}

\section{INTRODUCCIÓN}

El actual Sistema Europeo Común de Asilo (SECA) proporciona un rígido marco jurídico en la protección del derecho de asilo cuya finalidad eminentemente armonizadora se encuentra fuertemente cuestionada tras toda una serie de escenarios que han afectado directamente a la seguridad de los Estados miembros. La efectividad de este sistema se ha visto eclipsada por un amplio margen de apreciación nacional en la determinación de conductas que pueden poner en riesgo su seguridad, conectando, en ocasiones, la concesión de estatuto de protección internacional a un aumento de la criminalidad y terrorismo.

Los orígenes de este nexo causal se remontan a los atentados terroristas de Nueva York del 11-S en el año 2001, ${ }^{2}$ los cuales constituyeron una directa amenaza contra

1 Personal investigador en formación. Generalitat Valenciana (ACIF/2017). Departamento de Derecho Público. Edificio JC2. Facultad de Ciencias Jurídicas y Económicas. Universitat Jaume I. Avda. de Vicent Sos Baynat, s/n. E-12071 Castelló de la Plana. España (Spain). Email: jviguri@uji.es. El presente trabajo se ha elaborado en el marco del Proyecto Ministerio de Ciencia e Innovación titulado "La implementación del RGPD en España: El impacto de las cláusulas abiertas en la nueva LOPD, en su normativa de desarrollo y en la legislación sectorial (PRODATIES)”. Referencia: RTI2018-095367$\mathrm{B}-\mathrm{IOO}$

2 Sobre este principal precedente, ha sido abordado por un amplio sector doctrina, entre otros: HUYSMANS, J. et BUONFINO, A. (2008). "Politics of exception and unease: immigration, asylum and terrorism in parliamentary debates in the UK", Political Studies, vol. 56, n 4, p. 767; KEPHART J. L. (2006). "Immigration and Terrorism: Moving Beyond the 9/11 Staff Report on Terrorist Travel", Connections, vol. 5, no. 2, p. 56; KERWIN D. (2016). "How Robust Refugee Protection Policies Can Strengthen Human and National Security", Journal on Migration and Human Security, vol. 4, n 3, p. 85; BAYLIS E. A. (2010). "National Security and Political Asylum" en: D’APPOLLONIA A. C., REICH S., (Eds.), Immigration, Integration, and Security: America and Europe in Comparative Perspective, University of Pittsburgh Press, p. 164; KAUNERT, C. (2011). European internal security - towards supranational governance in the area of freedom, security and justice?, Europe in Change, Manchester University Press, Man- 
la seguridad europea e internacional y propiciaron una liberalización mundial de las políticas de inmigración y asilo. Se alzaron voces críticas y de advertencia por parte del Alto Comisionado de Naciones Unidas para los Refugiados (ACNUR) que expresó su preocupación de que, los solicitantes de asilo y los refugiados, fueran víctimas de políticas excesivamente restrictivas y vinculadas con frecuentes excepciones radicadas en seguridad nacional. ${ }^{3}$ En este contexto, también, la Comisión de las Comunidades Europeas mostró su preocupación por el hecho de que los terroristas emplearan fraudulentamente el procedimiento de asilo e instó, por primera vez, a examinar la conexión entre la salvaguarda de la seguridad interior y el cumplimiento de las obligaciones e instrumentos internacionales en materia de protección internacional. ${ }^{4}$

Una relación que ha reducido, con otro cariz y a pesar de los grandes avances producidos en la materia, la coherencia del SECA, condicionada por políticas focalizadas tanto en la prevención exacerbada de los distintos ataques terroristas acaecidos en Europa como en la incapacidad de asumir las grandes afluencias de refugiados en tiempos de crisis.

En la actualidad, los distintos contextos especialmente convulsos en la relación entre las legítimas preocupaciones por la seguridad y la preservación de este derecho han avivado la reticencia de los líderes europeos a reconocer un amplio número de refugiados ante una subjetiva percepción de "incompatibilidad".

Las cuestiones relativas a la seguridad han rebajado sustancialmente las garantías previstas en el SECA ante reiteradas y persistentes excepciones que han excedido de su finalidad eminentemente restrictiva, propiciando continuas prácticas nacionales contrarias a los fines y objetivos de esta normativa, del Convenio Europeo de los Derechos Humanos, de la Carta de Derechos Fundamentales de la UE, así como de las propias obligaciones internacionales previstas en la Convención de Ginebra de 1951 y el Protocolo de Nueva York de 1967 sobre el estatuto de los refugiados.

Sobre esta cuestión, el Servicio de Investigación del Parlamento Europeo afirmaba en 2018 que la lucha contra el terrorismo se empleaba como "pretexto" para limitar generalizadamente derechos fundamentales. ${ }^{5}$ Además, un reciente estudio contabilizó los términos más empleados por los Estados miembros en la gestión de la migración

chester, p. 72; SERRA CRISTÓBAL, R. (2016). Los derechos fundamentales en la encrucijada de la lucha contra el terrorismo yihadista. Lo que el constitucionalismo y el derecho de la Unión Europea pueden ofrecer en común, Teoría y Realidad Constitucional, nº 38, p. 487.

3 ACNUR, "Ten Refugee Protection Concerns in the Aftermath of Sept. 11", Press Release, Geneva, 23 October 2001. Igualmente, la Asamblea General de Naciones Unidas subrayó que éstos establecían peligrosos nexos "injustificados entre la protección de los refugiados y las amenazas terroristas". Asamblea General de Naciones Unidas (AGNU), Protección de los derechos humanos y las libertades fundamentales en la lucha contra el terrorismo - Nota del Secretario General (A/62/263), 15 de agosto de 2007.

${ }^{4}$ Comisión de las Comunidades Europeas, «Documento de trabajo de la Comisión: Relación entre salvaguarda de la seguridad interior y cumplimiento de las obligaciones e instrumentos internacionales en materia de protección», COM (2001) 743 final, Bruselas, de 5 de diciembre de 2001.

${ }^{5}$ Van BALLEGOOIJ W. et BAKOWSKI P. (2018). The cost of non-Europe in the fight against terrorism, EPRS, European Parliament. 
y asilo en el que relevador resultó el masivo uso de conceptos como crisis, seguridad, control, detención, retorno, irregular, ilegal, etc. ${ }^{6}$

De este modo, el papel clave de esta dimensión de seguridad ha limitado excesivamente los derechos de los solicitantes de protección internacional, trasladando este debate más allá del diálogo políticamente común que ha acrecentado la recurrente aplicación de medidas de seguridad. Un alcance que, en opinión de la Federación Internacional de Derechos Humanos, ${ }^{7}$ resulta extensible a escala global y que ha llevado a una regresión injustificada de los derechos humanos y las libertades fundamentales. Las incoherentes y dispares actuaciones de los Estados miembros exigen replantear el concepto de seguridad en la propuesta de reforma del SECA. Ello ha obligado a una profunda reflexión global que conecta directamente dos aspectos básicos de la UE, el «Espacio de Libertad, Seguridad y Justicia» y la seguridad, migración y asilo.

El presente trabajo analiza en primer término, la vinculación entre asilo y seguridad nacional en el actual SECA a través de toda una serie de acontecimientos que han aproximado ambas vertientes ofreciendo, desde una triple perspectiva, datos que constatan la necesidad de desconexión. En segundo lugar, se estudia el impacto de la seguridad en la propuesta de reforma del SECA. Una propuesta que, pese a que perfecciona jurídicamente este potencial conflicto, trasladando las cuestiones relativas a la seguridad desde el seno de los Estados miembros hacia el ámbito comunitario, lo cierto es que no logrará ofrecer respuesta a todas las situaciones sensibles en el ámbito nacional. En tercer lugar, abordaremos uno de los mayores desafíos que plantea a la efectividad del propio SECA, tal y como ya advierten la CE, Europol y el Comité Meijers, fenómenos completamente actuales como la radicalización y el reclutamiento que podrían facultar a continuar restringiendo este derecho sobre la base de la prevención del terrorismo comunitario.

\section{LOS PROBLEMAS RELATIVOS A SEGURIDAD Y SU ALCANCE EN EL ACTUAL SISTEMA EUROPEO COMÚN DE ASILO (SECA).}

\subsection{El impacto de la seguridad nacional en el actual SECA.}

Actualmente, de forma sinóptica, el objetivo principal del SECA es el establecimiento de criterios mínimos comunes para el tratamiento de todos los solicitantes y las solicitudes de asilo en toda la UE, armonizando y unificando los criterios de reconocimiento de protección internacional, los procedimientos de asilo y los diferentes sistemas nacionales de acogida en los países europeos.

${ }^{6}$ Sobre este estudio, remitimos a: SCHWEITZER, R., CONSTERDINE E. et COLLYER, M. (2018). A review and analysis of the recent literature on the Common European Asylum System, CEASEVAL, Research on the Common European Asylum System, nº 03, Chemnitz, p. 11.

${ }^{7}$ Federación Internacional de Derechos Humanos (FIDH), The United Nations Counter-Terrorism Complex, Bureaucracy, Political Influence and Civil Liberties, $\mathrm{n}^{\circ} 700$, septiembre de 2017, p. 14. 
Recordemos que los cinco instrumentos jurídicos adoptados durante la primera fase del SECA entre 2002 y 2005 fueron sometidos a una extensa evaluación y modificación cuya reforma concluía en su totalidad en el año 2013, salvo la Directiva de protección temporal del año $2001 .^{8}$ La normativa que desarrolla esta segunda fase del SECA se ha compuesto desde sus inicios, básicamente, de dos reglamentos (Dublín y Eurodac) ${ }^{9}$ y de tres directivas (reconocimiento, acogida y procedimiento). Mientras que la dimensión de la seguridad nacional no se encuentra prevista en el reglamento de Dublín o se contempla en Eurodac desde un enfoque puramente técnico, esto es, tratando la seguridad de los datos (considerando $27,43 \mathrm{o}$ art. 4.1$),{ }^{10}$ todas las directivas que conforman el SECA han previsto constantes excepciones radicadas en seguridad con objeto de garantizar la salvaguarda de la seguridad de los estados.

Por una parte, la Directiva de reconocimiento 2011/95/UE dispone en el considerando 37 la aplicación del concepto de seguridad nacional y de orden público a nacionales

${ }^{8}$ Esta Directiva fue la única excepción de refundición, pese a prever una respuesta común de la UE a la afluencia de personas desplazadas a gran escala que no podían regresar a sus países de origen. Esta directiva no fue ni siquiera activada tras las crisis migratorias acaecidas en 2015-2016, pese a las respuestas eficientes que hubiera proporcionando en la "descongestión" de los sistemas de asilo nacionales "de primera línea". European Commission, Study on the Temporary Protection Directive, Executive Summary, enero 2016, p. 2. Es más, el Parlamento instó al Consejo a que considerara seriamente la posibilidad de activarla en virtud del art. 78.3 TFUE, previendo la aplicación del mecanismo de solidaridad en los supuestos de entradas masivas y repentinas de personas desplazadas. Directiva 2001/55/CE del Consejo, de 20 de julio de 2001, relativa a las normas mínimas para la concesión de protección temporal en caso de afluencia masiva de personas desplazadas y a medidas de fomento de un esfuerzo equitativo entre los Estados miembros para acoger a dichas personas y asumir las consecuencias de su acogida. OJ L 212, 7.8.2001, p. 12-23.

9 Reglamento (UE) n 604/2013 del Parlamento Europeo y del Consejo, de 26 de junio de 2013 , por el que se establecen los criterios y mecanismos de determinación del Estado miembro responsable del examen de una solicitud de protección internacional presentada en uno de los Estados miembros por un nacional de un tercer país o un apátrida, OJ L 180, 29.6.2013, p. 31-59; Reglamento (UE) n 603/2013 del Parlamento Europeo y del Consejo, de 26 de junio de 2013, relativo a la creación del sistema «Eurodac» para la comparación de las impresiones dactilares para la aplicación efectiva del Reglamento (UE) n ${ }^{\circ} 604 / 2013$, por el que se establecen los criterios y mecanismos de determinación del Estado miembro responsable del examen de una solicitud de protección internacional presentada en uno de los Estados miembros por un nacional de un tercer país o un apátrida, y a las solicitudes de comparación con los datos de Eurodac presentadas por los servicios de seguridad de los Estados miembros y Europol a efectos de aplicación de la ley, y por el que se modifica el Reglamento (UE) n 1077/2011, por el que se crea una Agencia europea para la gestión operativa de sistemas informáticos de gran magnitud en el espacio de libertad, seguridad y justicia, OJ L 180, 29.6.2013, p. 1-30.

${ }^{10}$ Directiva 2011/95/UE del Parlamento Europeo y del Consejo, de 13 de diciembre de 2011, por la que se establecen normas relativas a los requisitos para el reconocimiento de nacionales de terceros países o apátridas como beneficiarios de protección internacional, a un estatuto uniforme para los refugiados o para las personas con derecho a protección subsidiaria y al contenido de la protección concedida. OJ L 337, 20.12.2011, p. 9-26; Directiva 2013/33/UE del Parlamento Europeo y del Consejo, de 26 de junio de 2013, por la que se aprueban normas para la acogida de los solicitantes de protección internacional, OJ L 180, 29.6.2013, p. 96-116; Directiva 2013/32/UE del Parlamento Europeo y del Consejo, de 26 de junio de 2013, sobre procedimientos comunes para la concesión o la retirada de la protección internacional, OJ L 180, 29.6.2013, p. 60-95. 
de terceros país pertenecientes a una asociación que apoya o respalda el terrorismo internacional. Además, esta Directiva ha articulado un conjunto de excepciones por este motivo en diversos ámbitos como el régimen de exclusión (arts. 12 y 17.1 d), la revocación del estatuto (art. 14.4 a)), la expulsión (art. 21.2 a)) incluso estableciendo excepciones en el ámbito del mantenimiento de la unidad familiar (art. 23.4), en la expedición de permisos de residencia (art. 24) o documentos de viaje (art. 25). Por otra parte, la Directiva de acogida 2013/33/UE regula también toda una serie de extremos conexos a la seguridad, como el internamiento (art. 8.3 e)), limitaciones de acceso de familiares, los asesores jurídicos o consejeros o las personas representantes de organizaciones no gubernamentales competentes (art. 10.4). Finalmente, la Directiva de procedimiento 2013/32/UE exceptúa su aplicación al mantenimiento del orden público y salvaguardia de la seguridad interior (considerando 51). Igualmente, dispone la adopción del procedimiento acelerado en caso de que el sujeto pueda considerarse un potencial delincuente o terrorista (considerando 20 y art. 31.8 j), así como limitaciones de acceso a la información y asesoramiento en centros de internamiento y en puestos fronterizos (art. 8.2), excepciones en el registro de los solicitantes (art. 13.2 d)) o en el alcance de la asistencia jurídica y de la representación legal (art. 23.1). Con ello, resulta patente que el régimen de excepción de la seguridad se encuentra previsto en prácticamente todos los instrumentos jurídicos del SECA.

Sobre estas extensas excepciones, conviene apuntar que el art. 4.2 TFUE exige una aplicación restringida de esta dimensión con miras a garantizar la aplicación coherente del derecho comunitario. ${ }^{11}$ Sin embargo, se ha concedido excesiva flexibilidad a los Estados miembros para abordar aspectos que penden directamente de su soberanía, careciendo de una contundente respuesta eficaz en el equilibrio necesario entre la protección de esta institución y las cuestiones ligadas a la seguridad. Ello, pese a que un sector de la doctrina argumente que la seguridad no constituye una cláusula de reserva compentencial exclusiva para los Estados miembros aunque, en último extremo, continúe siendo una cuestión fundamentalmente estatal por lo que concierne a cada estado la responsabilidad de asegurarla. ${ }^{12}$

Concretamente, la aplicación de las mencionadas excepciones se hizo patente tras la «crisis migratorias y de refugiados» en la UE acaecida durante los años 2015 y 2016, la cual provocó enormes brechas en la seguridad europea y aproximaron la relación entre asilo y terrorismo. Esta crisis, catalogada como una de las más desalentadoras

11 Este supuesto, que fue analizado por la conocida STJUE Comisión contra Italia de 15 de diciembre de 2009 (Asunto C-387/05), estableció el carácter restrictivo de la seguridad y determinaba que, si bien los Estados miembros resultaban competentes en la determinación de medidas concretas para asegurar su seguridad interior y exterior, no era menos cierto que éstos se encontraban sujetos a ciertos límites con objeto de garantizar la aplicación coherente del derecho comunitario.

12 De WITTE B. (2017). “Exclusive Member State Competences - Is There Such a Thing?”, en: GARBEN, S. GOVAERE I., (eds.), The Division of Competences Between the EU and the Member States: Reflections on the Past, the Present, and the Future, Portland, OR: Hart Publishing, p. 98; SERRA CRISTÓBAL R. (2018). "El control de datos de circulación de personas en la UE como mecanismo de salvaguarda de la seguridad nacional", Revista de derecho politico, n'. 102, p. 311.

(C) UNED. Revista de Derecho Politico

N. 107 , enero-abril 2020, págs 303-335 
desde la Segunda Guerra Mundial, ${ }^{13}$ cuestionó los valores intrínsecos de la identidad europea previstos en el art. 2 TUE, resultando una intolerable aparente situación de normalidad a la falta de apoyo uniforme por parte de los Estados miembros y tras la aplicación de generalizadas políticas de seguridad.

La vis attractiva de la dimensión de seguridad nacional resulta constatable ante una serie de actuaciones estatales que han otorgado especial preeminencia a la seguridad de los Estados miembros y que ha provocado una excesiva flexibilización de las disposiciones que regula el SECA. Como en su momento ya reflejaba De Vergottini, la predisposición y el papel dominante de la seguridad tiende a ser protegido de un modo riguroso en detrimento de la libertad ${ }^{14}$ y cuyo reflejo, a día de hoy, se aprecia en las políticas nacionales de asilo, que parecen diseñarse bajo un prisma restrictivo; abordando directamente los factores que ponen en serio riesgo su seguridad; sorteando y evitando la tramitación de solicitudes de protección internacional y por ende, reduciendo el despliegue de medios administrativos y económicos comúnmente limitados en el ámbito nacional. Ello, a pesar de que el objetivo del SECA sea precisamente, la plena convergencia entre los sistemas nacionales de asilo, el establecimiento de un sistema más eficiente que permita reducir los movimientos secundarios, la lucha contra los abusos, así como brindar un mayor apoyo a Estados miembros especialmente afectados por la presión migratoria.

El actual SECA reconoce expresamente el derecho de los distintos estados a administrar de manera responsable los flujos migratorios y de protección internacional dentro de sus fronteras mediante el diseño de salvaguardas contra el abuso de esta institución y la protección de cualquier hecho que ponga en riesgo su propia seguridad. El problema radica en que este sistema, como subrayó García Mahamut durante las crisis migratorias, se ha visto supeditado a todo un marco jurídico nacional que ha obstaculizado — en mayor o menor medida — la efectividad y garantías del SECA, dificultando gravemente la consecución de sus objetivos. ${ }^{15}$ De este modo, Porras Ramírez apunta a que las competencias de la UE en materia de control de fronteras, asilo e inmigración, se encuentran "mediatizadas" por la finalidad de salvaguardar la seguridad ${ }^{16}$ y cuya traslación resulta manifiesta ante las reiteradas políticas nacionales opuestas a los fines y objetivos del SECA.

${ }^{13}$ Esta magnitud inédita de las crisis de refugiados ha sido analizada, entre otros, por: GONZÁLEZ ENRÍQUEZ, C. (2015). "La crisis de los refugiados y la respuesta europea", Análisis del Real Instituto Elcano de Estudios Estratégicos. ARI 67/2015, pp. 1-13. PUIG DE LA BELLACASA, R. (2016). "Europa ante sí misma”, Claves de Razón Práctica, n 244, pp. 9-19.

14 De VERGOTTINI, G. (2004). "La difícil convivencia entre libertad y seguridad. Respuestas de las democracias al terrorismo", Revista de Derecho Político, no 61, p. 35.

15 GARCÍA MAHAMUT, R. (2016). "La ductilidad del derecho a la protección internacional (refugio y protección subsidiaria) ante las crisis humanitarias: un desafío para Europa y para el Sistema Común de Asilo", Teoría y Realidad Constitucional, no 38, p. 234.

16 PORRAS RAMÍREZ, J. M. (2017). El sistema europeo común de asilo y la crisis de los refugiados. Un nuevo desafío de la globalización. Revista de Estudios Políticos, nº 175, p. 211. 
El refuerzo de la gestión integrada de fronteras con miras a luchar eficazmente contra el terrorismo y la protección efectiva de los solicitantes de protección internacional fue especialmente revelador en la Estrategia Global para la Política Exterior y de Seguridad de la UE en el Consejo Europeo de junio de 2016. ${ }^{17}$ Una Estrategia que adolecía no solo de una falta de concreción en el difuso y amplio concepto de solidaridad, sino que tampoco proporcionaba pautas claras en la determinación de los parámetros de seguridad y terrorismo en el ámbito de la protección internacional.

Igualmente, meses antes, la Comisión Europea (CE) había propuesto la reforma del SECA en su conjunto, ${ }^{18}$ ante la imperante necesidad de solventar los efectos tan desventajosos y contrarios a la propia normativa internacional, que se agravaron ante las restricciones tanto en fronteras interiores como exteriores de la UE, así como el repunte de los atentados terroristas en diversos países de la UE. Ello originó que las cuestiones de lucha contra el terrorismo encabezaran la agenda política tanto en el plano nacional como de la UE.

Ahora bien, el alcance de la mencionada propuesta no implicó, a priori, vinculación directa alguna entre seguridad y asilo, sino que se focalizaba principalmente en la gestión integrada de fronteras, elemento nuclear para el mantenimiento de la seguridad en la UE. Pese a todo, no fue hasta 2017 cuando se produjeron destacados avances en la desvinculación entre seguridad y derecho a la protección internacional. En primer lugar, el grupo de seguridad interno en el Consejo Europeo destacó que la prevención de la llegada de migrantes ilegales constituía el principal problema para garantizar la seguridad de la UE. ${ }^{19}$ Seguidamente, la Agenda Europea de Migración, adoptada el 27 de septiembre de $2017,{ }^{20}$ hizo un primer balance de los principales logros y deficiencias en su aplicación en la que alejaba los problemas relativos a la seguridad a cuestiones intrínsecas del derecho a la protección internacional, salvo las

${ }^{17}$ La mencionada Estrategia, sustituyó a la primera Estrategia Europea de Seguridad (EES) del año 2003, que se ocupó de la dimensión exterior de la seguridad de Europa. (Estrategia Europea de Seguridad, Una Europa Segura en un mundo mejor, Bruselas, 12 de diciembre de 2003, p. 8). Esta Estrategia fue completada con la adopción de la Estrategia de Seguridad Interior en febrero de 2010, aprobada por el Consejo Europeo de los días 25 y 26 de marzo de ese año, que tipificaba la seguridad, libertad y justicia como políticas que se reforzaban mutuamente, respetando los derechos fundamentales, la protección internacional, el Estado de Derecho y la intimidad. (Consejo Europeo, Estrategia de Seguridad Interior de la Unión Europea. Hacia un modelo europeo de seguridad, Doc. 5842/2/2010, marzo de 2010, p. 19).

Sobre esta última Estrategia, véase: Servicio Europeo de Acción Exterior, Una visión común, una actuación conjunta: una Europa más fuerte, Estrategia global para la política exterior y de seguridad de la Unión Europea 28 y 29 de junio de 2016.

${ }_{18}$ Comisión Europea, Comunicación de la Comisión al Parlamento Europeo y al Consejo «Hacia una reforma del Sistema Europeo Común de Asilo y una mejora de las vías legales a Europa», $\operatorname{COM}(2016) 197$ final, Bruselas, de 6 de abril de 2016.

19 EUObserver, "El contrabando de migrantes encabeza las prioridades delictivas de la UE", 10 de octubre de 2017.

${ }^{20}$ Comisión Europea, Comunicación de la Comisión al Parlamento Europeo, al Consejo, al Comité Económico y Social europeo y al Comité de las Regiones «relativa al cumplimiento de la Agenda Europea de Migración», COM(2017) 558 final, de 27 de septiembre de 2017. 
oportunas acciones sobre las que debían otorgarse prioridad para lograr una política europea de asilo y migración más eficiente, justa y estable.

En la actualidad, a pesar de estas pertinentes iniciativas, las excepciones nacionales continúan desvirtuando el "mínimo denominador común" del SECA, creando un marco jurídico especialmente fragmentado e incompatible con las obligaciones europeas e internacionales en el ámbito de la protección internacional. Así, las garantías del actual SECA se han visto reducidas por la apreciación nacional que vincula la concesión de este estatuto a una mayor tasa de criminalidad.

Ello exige una profunda revisión acerca del verdadero nexo entre los problemas relativos a la seguridad y, especialmente, de ataques terroristas con la concesión de estatuto de protección internacional. Máxime, teniendo en consideración que, la nueva propuesta de reforma del SECA, no solo no parece restringir el margen de apreciación nacional —al prever idénticas excepciones que en las actuales Directivas- ${ }^{21}$ sino que pretende ampliar el propio concepto de seguridad nacional y de orden público en plena sintonía con las Resoluciones de Naciones Unidas sobre el particular. Y más concretamente, en dos supuestos: 1) en el caso de que un nacional de un tercer país pertenezca a una asociación que meramente "apoya" o "respalda" el terrorismo internacional (considerando 45 de la propuesta de Reglamento de reconocimiento) y 2) en relación con la exclusión del estatuto de protección internacional, previéndose la inclusión de comisión de actos terroristas, focalizados por su violencia hacia la población civil, incluso si se persigue un supuesto objetivo político (art. 12.5 b) de la mencionada propuesta).

\subsection{Desmitificando la actual correlación entre asilo y terrorismo.}

El "inexorable obstáculo" entre los problemas relativos a la seguridad ha rebajado de protección los actuales estándares europeos de asilo, principalmente tras los ataques

${ }^{21}$ La propuesta de Directiva de acogida prevé limitaciones en el internamiento (art. 8.3f)), la propuesta de Reglamento de procedimiento establece la restricción de acceso a la información (art. 16.2), el examen mediante procedimiento acelerado (art. $40.1 \mathrm{f}$ ) y $40.5 \mathrm{~b}$ )) y el procedimiento fronterizo (art. 41.5 b)), ambos por razones de seguridad nacional. Por lo que respecta a la propuesta de Reglamento de reconocimiento, no solo se mantienen las idénticas excepciones en el ámbito de la seguridad nacional sobre las cuestiones del mantenimiento de la unidad familiar (art. 25.4), permisos de residencia (art. 26.2 c)) o documentos de viaje (art. 27.3). Véase: Comisión Europea, Propuesta de Directiva del Parlamento Europeo y del Consejo por la que se aprueban normas para la acogida de los solicitantes de protección internacional (texto refundido), COM(2016) 465 final; Propuesta de Reglamento (...) por el que se establecen normas relativas a los requisitos para el reconocimiento de nacionales de terceros países o apátridas como beneficiarios de protección internacional, a un estatuto uniforme para los refugiados o para las personas con derecho a protección subsidiaria y al contenido de la protección concedida y por el que se modifica la Directiva 2003/109/CE del Consejo, de 25 de noviembre de 2003, relativa al estatuto de los nacionales de terceros países residentes de larga duración, $\operatorname{COM(2016)} 466$ final; Propuesta de Reglamento (...) por el que se establece un procedimiento común en materia de protección internacional en la Unión y se deroga la Directiva 2013/32/UE. 
terroristas que se han producido en suelo europeo, concentrados entre 2015 y $2017 . .^{22}$ La Comisión Española de Ayuda al Refugiado (CEAR) advertía que tras la comisión de estos ataques, "los decibelios de las mentiras alcanzan cotas dantescas para desgracia de las personas migrantes y refugiadas, especialmente de países musulmanes, que se convierten inmediatamente en sospechosas por su origen y su religión". ${ }^{23}$ También un experto de Naciones Unidas en la lucha antiterrorista exigía no solo la desvinculación del terrorismo de la condición de refugiado, sino el imperante deber de investigar las causas concretas e individuales que podían relacionar ambas vertientes. ${ }^{24}$

Sobre esta cuestión, conviene destacar que los incidentes terroristas cometidos directa o indirectamente por solicitantes de asilo o refugiados resultan residuales pese a su notoria entidad en los últimos años. No cabe, en modo alguno, soslayar un dato de enorme relevancia: casi 5 millones de solicitudes de asilo y protección subsidiaria se han presentado entre los años 2014 y 2019 en los 28 Estados miembros. ${ }^{25}$

En esta línea se pronunció el ACNUR, que constataba una rotunda separación entre asilo y terrorismo. ${ }^{26} \mathrm{Si}$ bien, en el ámbito comunitario, se hizo especial énfasis en la necesidad de adoptar un enfoque holístico e integral entre el diseño políticas nacionales de seguridad y su impacto en el asilo, especialmente tras la perpetración

${ }^{22}$ El ataque terrorista perpetrado en Le Bataclan en noviembre de 2015 en París se corona como uno de los casos por excelencia que sustentan el nexo asilo-terrorismo. En otros casos, adquieren una considerable repercusión social, como el ataque con arma blanca por parte de un solicitante de asilo afgano menor de edad en un tren alemán en julio de 2016 o el atentado perpetrado por un asilado tunecino en Berlín que había llegado en 2011 a la isla de Lampedusa con un camión en diciembre de 2016. Otro solicitante de asilo uzbeko en Estocolmo llevó a cabo un atentado en mayo de 2017. Además, un artefacto explosivo fue descubierto y desactivado en abril de 2017 cerca de una estación de metro en el barrio de Gronland, en Oslo (Noruega) donde las autoridades arrestaron a un solicitante de asilo ruso de 17 años de edad, identificado como un extremista de inspiración yihadista relacionado con el incidente. Ese mismo año, el ataque terrorista en el estadio de Manchester en mayo de 2017 fue perpetrado por parte del hijo de un refugiado perteneciente al Grupo de Lucha Islamista Libio que había llegado a Inglaterra en los años 90. No se han reportado incidentes terroristas cometidos por sujetos relacionados con la institución de protección internacional durante los años 2018 y 2019. La identificación de estos ataques terroristas ha sido extraídos de la Base de Datos de Terrorismo Global (GTD), Centro de Excelencia del Departamento de Seguridad Nacional de EEUU, adscrito a la Universidad de Maryland. Para más información, véase: https://www.start.umd.edu/gtd/

${ }^{23}$ Informe 2018 CEAR: Personas refugiadas en España y Europa, p. 68. Accesible en: https://www. cear.es/wp-content/uploads/2018/06/Informe-CEAR-2018.pdf.

${ }^{24}$ United Nations, Human Rights, Office of the High Commissioner, "Refugees and terrorism: 'No Evidence of Risk' - New report by UN expert on counter-terrorism," New York, 21 de octubre de 2016.

25 De acuerdo con Eurostat, fueron presentadas: 561.625 en 2014, 1.226.346 en 2015, 1.204.280 en 2016, 649.855 en 2017, 581.000 en 2018 y 639.000 en 2019.

${ }^{26}$ ACNUR, Guterres señalaba que resultaba "absolutamente absurdo" culpar a los refugiados por el terrorismo, 17 de noviembre de 2015 .

Accesible en: https://www.acnur.org/noticias/noticia/2015/11/5b7e712e13/guterres-senala-que-es-absolutamente-absurdo-culpar-a-los-refugiados-por-el-terrorismo.html?query=terrorismo

(C) UNED. Revista de Derecho Político

313

N.o 107, enero-abril 2020, págs 303-335 
de los distintos ataques terroristas. ${ }^{27}$ También se apuntó a que las políticas de inmigración y asilo en sede nacional resultaban ajenas a los potenciales riesgos que se generaban tras la aceptación de grandes afluencias de personas. ${ }^{28}$

Pese a todo, conviene subrayar que los refugiados representan una proporción muy reducida de todos los migrantes cuya automática consideración de amenaza a la seguridad de los Estados miembros supone no solo una flagrante discriminación y criminalización de este colectivo, sino también una vulneración de la Convención de Ginebra, de la Carta de Derechos Fundamentales, y del SECA en su conjunto. Sin embargo, las políticas restrictivas de asilo vinculadas a la amenaza para la seguridad del país de acogida se agravaron tras las crisis migratorias a gran escala en Europa. La incapacidad de asumir ingentes cantidades de solicitudes en puntos fronterizos concretos, así como de distinguir exhaustivamente a los verdaderos refugiados de potenciales terroristas que estaban actuando en distintos Estados miembros propiciaron que, ambas categorías de sujetos, fueran directamente considerados como amenazantes para la seguridad nacional.

Recuérdese que diez de los veinte ataques terroristas más letales desde 2000 en la OCDE acaecieron entre 2015 y 2016. Se cobraron la vida de 579 personas, resultando alrededor de 2.000 personas heridas. Además, los atacantes en ocho de estos diez ataques tenían alguna vinculación con el ISIS. ${ }^{29}$ Por lo que respecta a este apartado, merece una especial atención la aproximación que suele realizarse entre la concesión de estatuto de asilo y su directo impacto en los incidentes terroristas que han sufrido distintos Estados miembros y que aquí lo examinaremos desde una triple variable.

1. En cuanto a la procedencia/nacionalidad de los solicitantes de protección internacional. En los últimos años, el auge del terrorismo islámico con Al-Qaeda, Hezbollah y el Estado islámico en Iraq y Siria facilitó que un amplio número de sujetos solicitaran protección internacional en Europa en comparación con nacionales de otros países, ralentizando, en su caso, la concesión del estatuto de protección internacional. De acuerdo con Eurostat, ${ }^{30}$ durante 2015-2016, los solicitantes de protección internacional procedieron mayoritariamente de Siria, Afganistán, Albania, aunque también de Kosovo e Iraq, prácticamente por las solicitudes presentadas en Alemania, especialmente elevadas en relación a los otros países analizados. Entre 2017-2018, las solicitudes siguieron proviniendo principalmente de estos países, aunque en 2019 se apreció un cierto cambio de tendencia. Tras Siria y Afganistán,

${ }^{27}$ AVDAN N. (2014). "Do asylum recognition rates in Europe respond to transnational terrorism? The migration-security nexus revisited", European Union Politics, vol. 15, n 4, 2014, p. 467.

28 SIMCOX R., The Asylum-Terror Nexus: How Europe Should Respond, The Heritage Foundation, junio de 2018.

29 Institute for Economics and Peace, IEP (2016). Global Terrorism Index, Measuring and understanding the impact of terrorism, p. 42.

30 EUROSTAT, "Five main citizenships of (non-EU) asylum applicants 2014-2018, 14 de marzo de 2019. 
Venezuela se situó como el tercer país de solicitantes, principalmente tras su llegada a España ${ }^{31}$.

Prácticamente todos los Estados miembros registraron solicitudes procedentes de cuatro de los cinco países con un mayor número de muertes por terrorismo (Iraq en el número 1 mundial, Afganistán en el número 2, Siria en el $4^{\circ}$ lugar y Pakistán en el $5^{\circ}$ ), tal y como representa el Índice de Terrorismo Global. ${ }^{32}$ Desde el año 2015, han copado las cifras más elevadas de solicitudes de protección internacional (esencialmente en Alemania). Ello permite identificar un primer conflicto de aproximación entre protección internacional y terrorismo, ${ }^{33}$ en el que indudablemente la procedencia de la mayor parte de nacionales aumenta el grado de peligrosidad en comparación con otros terceros países de origen.

2. Ateniendo a la cuantificación de las entradas de solicitantes de asilo en cada país desde 2014, la base de datos de migración internacional de la Organización para la Cooperación y el Desarrollo Económicos (OCDE) y Eurostat ${ }^{34}$ proporcionan información clave sobre la cuestión.

El cénit de solicitudes de protección internacional en la UE se produjo durante 2015 y 2016 (excediendo el primer año de 1.300 .000 solicitudes y el segundo de 1.200.000 pero reduciéndose a casi la mitad en 2017 con poco más de 700.000). Estos datos resultaron sensiblemente menores en el caso de las solicitudes presentadas por primera vez (alrededor de 50.000 solicitudes menos aproximadamente en cada periodo). Una tendencia a la baja durante 2018, con un total de 580.800 solicitudes de protección internacional en los Estados miembros. Entre los países analizados, las entradas de solicitantes de asilo han aumentado progresivamente desde 2014 hasta 2018 en Francia y España mientras que países como Italia cayeron a más de la mitad durante 2018. Alemania también disminuyó drásticamente las solicitudes en los últimos tres años, en virtud de la cooperación con terceros países a través de programas de reubicación y reasentamiento (de 722.210 en 2016 a 198.260 en 2017 y 161.885 en 2018).

3. Finalmente, y tomando como referencia el número de entradas por país, así como la nacionalidad de los solicitantes, conviene examinar su relación con el número de ataques terroristas en los países analizados durante este mismo periodo de tiempo.

31 EUROSTAT, "First-time asylum-applicants in the EU28", diciembre de 2019.

${ }^{32}$ Datos de referencia tomados del Mapa interactivo del Índice de Terrorismo Global, 2019. http:// visionofhumanity.org/indexes/terrorism-index/

33 SCHMID, A.P. (2016). "Links between Terrorism and Migration: An Exploration", The International Centre for Counter-Terrorism - The Hague, no 4, p. 27.

34 Información consultada en la página web de la Organización para la Cooperación y el Desarrollo Económicos (OCDE) que dispone de la Base de datos de migración internacional así como Eurostat. Accesible en: http://www.oecd.org/els/mig/keystat.htm https://ec.europa.eu/eurostat/statistics-explained/index.php/Asylum_quarterly_report

(C) UNED. Revista de Derecho Politico

N. ${ }^{\circ}$ 107, enero-abril 2020, págs 303-335 
De conformidad con la Base de Datos de Terrorismo Global (GTD), ${ }^{35}$ Europa se ha enfrentado a un total de 47 atentados y se ha cobrado la vida de 618 personas en los países de Europa occidental. Asimismo, durante el periodo 2013 a 2017, los Estados miembros han tenido incidentes muy dispares entre ellos. Las cifras más altas las han copado Alemania (149), Francia (136) y Grecia (185). Mientras que en Alemania, el número de incidentes terroristas aumentaron en 2015 y 2016 (con altísimas solicitudes de protección internacional de 476.620 y 745.265 respectivamente y gran parte de ellos, de procedencia "crítica” como Siria, Afganistán, Iraq), en Grecia, la mayor parte acaecieron entre 2008 y $2010 .{ }^{36}$ Por lo que respecta a Italia, únicamente pueden contabilizarse 38 incidentes sostenidos regularmente entre 2013 a 2017 y en España, el número desciende a 17, de los cuales ninguno ha estado vinculado con la concesión de estatuto de protección internacional sino, más bien, con el extremismo islámico. ${ }^{37}$

En consecuencia, únicamente puede identificarse un aumento de incidentes terroristas durante la llegada masiva de refugiados entre los años 2015 y 2016 en Alemania. Durante estos dos años, fueron presentadas más de 1.200 .000 solicitudes, lo que equivalió a la totalidad de solicitudes de protección internacional tramitadas en todos los Estados miembros únicamente durante 2015 o 2016. Además, a esta situación se adicionó el hecho de que la mayor parte de las solicitudes resultaban de procedencia especialmente crítica, lo que parece evidenciar el aumento de incidentes terroristas. Aun así, esta vinculación resulta hipotética, puesto que las solicitudes de asilo superaron el millón por año.

Las elevadas solicitudes de asilo presentadas en un periodo limitado de tiempo y el hecho de que un alto porcentaje de solicitantes de asilo provinieran de Iraq, Afganistán, Pakistán o Siria pudieron aumentar la probabilidad de sufrir incidentes terroristas en el país germano que, en modo alguno, pueden extenderse al resto de países de la UE. Sin embargo, la idea de que combatientes del Estado Islámico (conocido como Daesh o ISIS) podían haber solicitado protección internacional "camuflados" entre grandes masas de migrantes justificó serias limitaciones en la efectividad de este

35 A tiempo de escrito de este artículo, los últimos datos proporcionados por la GTD datan del año 2017.

36 Es más, Grecia lleva experimentando incidentes terroristas de forma sistémica y duradera desde mediados de la década de 1970 en contra de sus instituciones, por parte, en mayor medida de grupos terroristas guerrilleros revolucionarios. Sobre esta cuestión, véase, KASSIMERIS, G. (2013). "Greece: The Persistence of Political Terrorism”, International Affairs, 89, n 1, p. 132.

37 Un total de 4 tuvieron lugar por extremismo islámico (3 de ellos con los únicos resultados de muertes y heridos, dos provenientes del atentado terrorista de Barcelona del 17/8/2017 y el otro en Cambrils el 18/8/2017). Además, el autor/es de 3 ataques no pudo calificarse con exactitud (uno de ellos cometido por un migrante en la frontera de Melilla el 25/7/2017, agrediendo a policías en un puesto fronterizo e hiriendo a uno de ellos) por lo que, en este último supuesto, no hay directa relación entre el estatuto de asilo concedido y la comisión de ataques terroristas o incidentes de gran magnitud. 
derecho. Ello, a pesar de que Europol esclarecía que únicamente los Países Bajos habían informado que operativos del Estado Islámico se habían hecho pasar por solicitantes de asilo en el año 2016. ${ }^{38}$

Por tanto, estos datos permiten constatar que la acogida de sujetos con estatuto de refugiado o de protección subsidiaria no puede relacionarse directamente con un auge de incidentes terroristas. Y en yuxtaposición, los Estados miembros deberían afianzar una política de protección efectiva hacia los solicitantes de protección internacional, teniendo muy presente que se produjeron 24 ataques en centros de asilo o individuos en Suecia (11), Finlandia (6), Alemania (6) o Italia (1) entre 2014 y 2016, la mayoría de ellos durante 2015 (8) y 2016 (9) de acuerdo con la GTD. Estos ataques, procedentes eminentemente de grupos xenófobos y contrarios a la inmigración ampliamente considerada, afectaron a solicitantes de asilo y refugiados donde, en la mayoría de los incidentes, fue empleado fuego con el fiel objetivo de incendiar los distintos centros de acogida. ${ }^{39}$

Como veremos en el siguiente apartado, esta fiel defensa vendrá solventada, en parte, a través de la reforma del SECA, que prevé no solo un novedoso régimen competencial más proporcional en virtud del Reglamento Dublín IV, sino que adopta procedimientos específicos más exhaustivos —en plena coordinación con nuevos organismos especializados en la concesión de protección internacional a terceros estados considerados "calientes" o con un mayor riesgo a la entrada de potenciales terroristas-, eficientes y plenamente garantes con el derecho a la protección internacional.

\section{LA SEGURIDAD EN LA PROPUESTA DEL SECA: CLAVES DE LA NUEVA REFORMA.}

La reforma del SECA pretende respetar plenamente el derecho interno, europeo e internacional en diversos ámbitos incluyendo respuestas contundentes a la gestión de la migración y el asilo y la lucha contra el terrorismo. Una propuesta que, prácticamente, cuatro años más tarde, sigue sin aprobarse incumpliendo los planes de la $\mathrm{CE}$, que previó que el Consejo Europeo alcanzaría un acuerdo político sobre la reforma general del SECA en junio de 2018. Un plazo que resultó ambicioso y poco realista, en especial, el Reglamento Dublín III, objeto de cuantiosos debates — todavía a día de hoy - entre los Estados miembros. De hecho, el último informe de progreso del

38 Europol (2017). EU Terrorism Situation and Trend Report (TE-SAT), La Haya, p. 14 y Europol (2019). EU Terrorism Situation and Trend Report (TE-SAT), La Haya, p. 32.

39 Una cifra que aumentó hasta los 93 ataques terroristas durante el mencionado periodo si, además, se incluyen aquellos incidentes individualmente considerados hacia refugiados y solicitantes de asilo. En este último supuesto, Alemania se corona con el mayor número de ataques de la OCDE con un total de 40 incidentes. Global Terrorism Index (2017). Measuring and understanding the impact of terrorism, p. 57; Europol (2017). EU Terrorism Situation..., op. cit., p. 10.

(C) UNED. Revista de Derecho Político 
Consejo sobre los siete instrumentos legislativos que conforman la propuesta presenta escasos avances en este sentido. ${ }^{40}$

La propuesta reviste innegable valor jurídico para abordar los contextos de seguridad y acomete - al menos teóricamente — toda una serie de cuestiones relativas a la seguridad nacional con la finalidad de elevar sustancialmente sus garantias hacia una genuina seguridad europea común. Para la consecución de estos objetivos, pivota su reforma sobre tres cuestiones clave:

1. Exceptuando la propuesta de Directiva de acogida, tanto la Directiva de procedimiento como la de reconocimiento sufren una radical transformación jurídica en reglamentos comunitarios con miras a solventar las graves deficiencias en la armonización de los procedimientos de asilo, así como las condiciones de reconocimiento. Esta reforma prevé un considerable aumento de la eficiencia en la identificación y prevención de brechas en la seguridad de los estados mediante el diseño de un novedoso "esquema complementario" entre las necesidades europeas/nacionales y las de los propios solicitantes. ${ }^{41}$ Ello permitirá una interrelación mejorada entre ambos extremos mediante la creación de un marco jurídico integrado que adecue las preocupaciones de seguridad nacional en el pleno cumplimiento de la vinculante propuesta del SECA.

2. El Reglamento Dublín III no ha ofrecido una contundente respuesta a las situaciones de presión desproporcionada sobre los sistemas nacionales de asilo, imponiendo una distribución de solicitudes, que resultó inasumible para ciertos estados concretos - esto es, aquellos que disponían de fronteras exteriores de la UE especialmente débiles desde un punto de vista geográfico, en especial, Italia y Grecia- e incentivó su incumplimiento en su tramitación exhaustiva, fundamentalmente tras los flujos masivos a gran escala de 2015 y 2016.

La nueva propuesta de Reglamento Dublín $\mathrm{IV}^{42}$ regula un novedoso mecanismo de acción correctora, que aporta un sistema competencial más

${ }^{40}$ En relación con la propuesta de Reglamento de Procedimientos, el Consejo debe todavía negociarla con el Parlamento Europeo. Por lo que respecta a la reforma del Reglamento de Dublín, el Consejo aún no ha aprobado un mandato de negociación con el Parlamento Europeo, pese a que este último, ya ha adoptado su posición. Consejo de la UE, Reforma del Sistema Europeo Común de Asilo y Reasentamiento. Informe de progreso 6600/19, 26 de febrero 2019. http://data.consilium.europa.eu/doc/ document/ST-6600-2019-INIT/ES/pdf

41 JONES W., TEYTELBOYM A. (2016). “The Refugee Match: A system that respects refugees' preferences and the priorities of states", Forced Migration Review online, p. 11; JONES, W., TEYTELBOYM, A. (2017). “The International Refugee Match: A System that Respects Refugees' Preferences and the Priorities of States", Refugee Survey Quarterly, vol. 36, Issue 2, p. 89; OWEN, D. (2019). "Refugees, EU Citizenship and the Common European Asylum System A Normative Dilemma for EU Integration”, Ethical Theory and Moral Practice, Springer, p. 10.

42 Propuesta de Reglamento del Parlamento Europeo y del Consejo por el que se establecen los criterios y mecanismos de determinación del Estado miembro responsable del examen de una solicitud 
eficiente, proporcional y justo con las necesidades nacionales sin limitar el margen de apreciación nacional en la determinación de conductas susceptibles de poner en riesgo la seguridad u orden público. Este reparto equitativo de responsabilidades entre los Estados miembros que dispone el Capítulo VII (arts. 34 y ss.), pondera continuamente el porcentaje de solicitudes de las que cada Estado miembro haya sido declarado responsable y lo compara con el porcentaje de referencia basado en una clave que tiene en cuenta la población y el PIB total de un Estado miembro. Su aplicación resultará automática cuando el número de solicitudes supere el $150 \%$ de la cifra indicada en la clave de referencia. Una solución a la sobrecarga e incapacidad de los flujos migratorios a gran escala que pretende evitar, o al menos reducir, que determinados Estados miembros afectados continúen imponiendo restricciones generalizadas en sus sistemas de asilo.

3. Finalmente, Eurodac, la base de datos especializada en asilo, prevé igualmente reforzarse mediante una mayor inclusión de datos personales y un régimen de intercambio de información interoperable entre los restantes sistemas de información europeos. Al margen del potencial conflicto de la seguridad con el derecho fundamental a intimidad, privacidad y protección de datos de los solicitantes de protección internacional y refugiados, coexiste una cierta tendencia a abordar estos problemas desde un enfoque coordinado supranacional, esto es, por medio de los futuros organismos especializados en gestión de fronteras como la futura Agencia de Asilo de la UE (AAUE) que sustituirá a la Oficina Europea de Apoyo al Asilo (EASO), ${ }^{43}$ una mejorada actuación de la Guardia Europea de Fronteras y Costas $(\mathrm{GEFC})^{44}$ y el despliegue de los novedosos equipos conjuntos de gestión de la migración de la UE integrados por estos dos organismos además de miembros de Europol y autoridades del Estado miembro afectado. ${ }^{45}$

No cabe duda de que la propuesta del SECA toma buen ejemplo de los déficits actuales, trasladando los problemas competenciales relativos a la seguridad y orden público desde el seno de los Estados miembros hacia el ámbito comunitario. Las

de protección internacional presentada en uno de los Estados miembros por un nacional de un tercer país o un apátrida (texto refundido), COM(2016) 270 final 2016/0133 (COD).

43 Propuesta de Reglamento del Parlamento Europeo y del Consejo relativo a la Agencia de Asilo de la Unión Europea y por el que se deroga el Reglamento (UE) n. ${ }^{\circ}$ 439/2010. COM/2016/0271 final - 2016/0131 (COD).

44 Reglamento (UE) 2019/1896 del Parlamento Europeo y del Consejo de 13 de noviembre de 2019 sobre la Guardia Europea de Fronteras y Costas y por el que se derogan los Reglamentos (UE) n. ${ }^{\circ}$ 1052/2013 y (UE) 2016/1624 (DOUE de 14 de noviembre de 2019).

45 Este nuevo órgano aparece contemplado en la nueva Propuesta modificada de Reglamento del Parlamento Europeo y del Consejo relativo a la Agencia de Asilo de la Unión Europea. Contribución de la Comisión Europea a la reunión de dirigentes celebrada en Salzburgo los días 19 y 20 de septiembre de 2018. COM(2018) 633 final 2016/0131 (COD), Bruselas, de 12 de septiembre, de 2018.

(C) UNED. Revista de Derecho Político

N. 107 , enero-abril 2020, págs 303-335 
cuestiones relativas a seguridad prevén abordarse "por defecto" mediante un gradual incremento de la efectividad de estas disposiciones y una mayor armonización que no restringirá el margen de apreciación nacional, sino que perfeccionará la actuación de los organismos asistenciales en fronteras exteriores.

En este sentido, la propuesta modificada de la CE supondrá la creación de la novedosa Agencia de Asilo de la UE con el fin de proporcionar un servicio eficiente y completo a los Estados miembros durante todo el procedimiento de asilo, contrarrestando y mitigando el fuerte despliegue policial en frontera. Los equipos conjuntos de gestión de la migración de la $\mathrm{UE}^{46}$, integrados por personal de la Agencia de Asilo de la UE, Frontex y Europol así como otras agencias europeas relevantes constituyen otras de las novedades incluidas en la mencionada propuesta. Sus actuaciones no solo revestirán especial importancia en los puntos críticos o botspots a instancia del Estado miembro solicitante, sino que serán claves para abordar una de los mayores retos que se producen a día de hoy — esto es, el tratamiento criminalizado de amplias categorías de sujetos sin una distinción exhaustiva entre personas en necesidad de protección internacional de otras que pueden comprometer la seguridad de los Estados miembros- Su despliegue se efectuará a petición del Estado miembro considerado "de acogida" y bajo la coordinación de la CE, que faculta a las distintas agencias y organismos de la UE su actuación "de apoyo".

Además, se otorgará un acceso al procedimiento de protección internacional coherente y adaptado a las necesidades nacionales en virtud de un renovado Reglamento Dublín y las fases procedimentales y el reconocimiento resultarán armonizadas gracias a la aplicación de los nuevos reglamentos comunitarios. Pese a ello, tal y como se analizarán en páginas posteriores, renacen nuevos desafíos que tienden a aproximar el hipotético y aparente nexo entre el asilo y el aumento de la criminalidad y terrorismo y que pueden poner en serio riesgo la efectividad del nuevo SECA.

\section{LA RADICALIZACIÓN COMO EXCEPCIÓN AL PARÁMETRO DE EVALUACIÓN DE LA SEGURIDAD EN EL SECA.}

\subsection{Retos emergentes de la radicalización y reclutamiento en el ámbito de la protección internacional.}

La diversidad y complejidad de los contextos terroristas y la adhesión de amplios grupos de sujetos desplazados a los objetivos perseguidos por grupos extremistas violentos ha ampliado la tipificación de conductas susceptibles de consideración radical, incluyendo como perfiles terroristas a difusas categorías de inmigrantes lega-

${ }^{46}$ Así establece la CE al referirse expresamente que: "los equipos pueden desplegarse para proporcionar una amplia tipología de actividades de apoyo al Estado miembro solicitante (...)”. Comisión Europea, A reinforced European Union Agency for Asylum - Questions and Answers, Commission - Fact Sheet, Estrasburgo, 12 de septiembre de 2018. 
les e ilegales a la par que refugiados políticos, entre otros. ${ }^{47}$ Qué duda cabe que la radicalización y el extremismo constituyen un trascendental reto para el mantenimiento de la seguridad europea.

Dicho lo anterior, y teniendo presente que no puede constatarse una correlación directa entre la concesión del estatuto de protección internacional con el aumento de ataques terroristas, fenómenos como el reclutamiento y la radicalización plantean una seria problemática cuando afecta al ámbito de la protección internacional. Estudios doctrinales sobre el particular, parecen poner de relieve que la radicalización de sujetos que ostentan el estatuto de refugiado constituye un riesgo de primer calado pues la probabilidad aumenta exponencialmente en comparación con otras categorías de sujetos. ${ }^{48} \mathrm{~A}$ esta situación se le adiciona la proximidad física y social de los solicitantes de protección internacional con los militantes islamistas radicales, organizaciones terroristas o dedicadas a la trata de seres humanos, especialmente, en fronteras exteriores de la UE.

Indudablemente, los escasos medios materiales y humanos comunitarios y nacionales para afrontar la radicalización enardecieron políticas nacionales de seguridad excesivamente restrictivas, dificultando el acceso al procedimiento, aplicando generalizadas cláusulas de exclusión, devolución, expulsión, reforzando sus fronteras exteriores e impidiendo la entrada de solicitantes de protección internacional.

Además, la amplitud de las posibles causas tanto previas como posteriores a la concesión del estatuto de protección internacional ha generado verdaderos problemas en la efectividad del derecho a la protección internacional en la UE. Por ejemplo, pueden atribuirse a un conjunto de factores individuales psicológicos producidos tras la huida, el choque cultural o la falta de inserción social en el estado de acogida y se extiende hasta el generalizado aumento de ataques xenófobos y la formulación de políticas nacionales fuertemente descompasadas con las necesidades específicas de este colectivo, especialmente, en los países receptores seriamente afectados por flujos migratorios a gran escala. El primer estudio sobre esta vinculación fue efectuado en los Países Bajos, que constató que la probabilidad de reclutamiento de refugiados por parte de grupos extremistas resultaba muy elevado, especialmente, aquellos que compartían estrechos vínculos sociales, religiosos o de identidad social con estas redes yihadistas. ${ }^{49}$

47 Esta primera aproximación fue abordada por NESSER, P. (2006). "Jihadism in Europe after the Invasion of Iraq: Tracing Motivational Influences from the Iraq War on Jihadism in Western Europe”, Studies in Conflict and Terrorism, vol. 29, nº. 4, p. 327; KOSER, K., CUNNINGHAM A. (2015). "Migration, Violent Extremism and Terrorism: Myths and Realities", en: Global Terrorism Index 2015: Measuring and Understanding the Impact of Terrorism Institute for Economics and Peace.

48 SCHMID, A., P. (2013). "Radicalisation, De-Radicalisation, Counter-Radicalisation: A Conceptual Discussion and Literature Review", The International Centre for Counter-Terrorism - The Hague 4, $\mathrm{n}^{\circ} .2$, p. 35 .

${ }^{49}$ De BIE, J. L., De POOT, C. J. et Van Der LEUN, J. P. (2014). "Jihadi networks and the involvement of vulnerable immigrants: reconsidering the ideological and pragmatic value", Global Crime, 15 (3-4), p. 282.

(C) UNED. Revista de Derecho Politico

N. 107 , enero-abril 2020, págs 303-335 
En 2014, la CE abordó la radicalización de este colectivo dando comienzo a una serie de estudios por parte de la Radicalisation Awareness Network (RAE). ${ }^{50}$ La práctica 2.5.8 titulada "Capacitar a los miembros del personal de los centros de acogida sobre prevención y denuncia del radicalismo" " se centraba, precisamente, en la identificación de actuaciones sospechosas y susceptibles de radicalización originadas en centros de acogida descuidados, con manifiesta falta de personal y con insuficientes medios materiales.

Estas condiciones propiciaron una peligrosa oleada propensa a la radicalización. Europol, un año más tarde, alertó acerca del especial riesgo de radicalización de una parte de refugiados sirios (musulmanes suníes), tras su llegada a Europa, constituían el principal objetivo de los reclutadores islamistas extremistas. ${ }^{52}$ Asimismo, la Estrategia Global sobre Política Exterior y de Seguridad de la UE de $2016^{53}$ destacó la lucha contra el extremismo violento y la radicalización como eje central de su política a pesar de que únicamente aludía a la necesidad de adoptar medidas efectivas para evitar la difusión de cualquier tipo de conducta o acción susceptible de proliferación de acuerdo con los valores intrínsecos de la UE, sin concretar medidas para abordar este cauce de potenciales ataques terroristas.

Con todo ello, la predisposición de que los refugiados desplazados puedan sumarse a los objetivos de los extremistas violentos exige la adopción de un nuevo modelo jurídico que adapte e integre las cuestiones esenciales en el mantenimiento de la seguridad europea y nacional a la protección efectiva de las personas desplazadas.

Si bien, a día de hoy, estas acciones carecen de estudios sobre su correlativo impacto en el SECA, ${ }^{54}$ pese a que, en los últimos tiempos, se han implementado políticas nacionales que se centran en la prevención de la radicalización de solicitantes de protección internacional y refugiados. Las primeras respuestas, proporcionadas a

${ }^{50}$ Comisión Europea, Comunicación de la Comisión al Parlamento Europeo, al Consejo, al Comité Económico y Social Europeo y al Comité de las Regiones, «prevenir la radicalización hacia el terrorismo y el extremismo violento: una respuesta más firme de la UE», COM (2013) 941 final, Bruselas, de 15 de enero de 2014, p. 2.

51 RAN Collection (2018). Preventing Radicalisation to Terrorism and Violent Extremism. Approaches and Practices.

${ }_{52}$ Europol (2016). European Union Terrorism Situation and Trend Report (TE-SAT), La Haya, p. 7.

53 Consejo de la Unión Europea, Conclusiones del Consejo relativas a la Estrategia Global sobre Política Exterior y de Seguridad de la Unión Europea-Conclusiones del Consejo (13202/16), 17 de octubre de 2016.

54 Actualmente, la radicalización se aborda desde una vertiente política, religiosa y social. Sobre estos parámetros, véase: ELEFTHERIADOU, M. (2018). "Refugee Radicalization/militarization in the age of the European refugee crisis: A Composite model”, Terrorism and Political Violence Journal; ANDRE V., F. MANSOURI, LOBO M., (2015). "A Fragmented Discourse of Religious Leadership in France: Muslim Youth between Citizenship and Radicalization," Journal of Muslim Minority Affairs, vol. 35, $\mathrm{n}^{\circ}$. 2, pp. 89-117; HALL J. (2016). “Are Migrants More Extreme than Locals after War? Evidence from a Simultaneous Survey of Migrants in Sweden and Locals in Bosnia” Journal of Conflict Resolution, $\mathrm{n}^{\circ}$ 60(1), pp. 89-117; NEUMANN P. R. (2016). "Radicalized: New Jihadists and the Threat to the West", Democracy and Security, vol. 13(4), London: IB Tauris, pp. 395-396. 
través de distintos programas en el Reino Unido, los Países Bajos, Dinamarca y Noruega, consideraron que resultaban más efectivas si tenían un objetivo específico sobre personas vulnerables o sujetos en vías de radicalización que las meras iniciativas proactivas. $^{55}$

Sin embargo, la complejidad en la determinación de las conductas susceptibles de comprometer la seguridad nacional y europea en un ámbito tan sensible como el asilo exige la adopción de nuevos mecanismos de coordinación sostenibles a largo plazo que igualmente, como destaca la $\mathrm{CE}$, deberán reunir a distintos actores desde un plano multinivel (local, regional, nacional y comunitario) para proceder a una exhaustiva identificación de conductas y patrones de comportamiento susceptibles de contrariar la seguridad nacional o europea. ${ }^{56}$ Además, debería implementarse una sinergia de estrategias y procedimientos coherentes que permitan la detección temprana de organizaciones terroristas que reclutan solicitantes de asilo o refugiados por medio de los distintos canales de información nacionales y europeos al efecto.

El futuro SECA potenciará las acciones de detección, prevención y supresión de conductas susceptibles de poner en riesgo la seguridad de los Estados miembros a través de una interoperabilidad sin precedentes de los sistemas de información aplicables al ámbito de la protección internacional. ${ }^{57}$ No obstante, como veremos a continuación, esta conectividad sin precedentes permanece ajena al surgimiento de estos nuevos desafíos en Internet, que exigen la firme apuesta de la UE por la implementación de un marco preventivo que permita afrontar potenciales acciones terroristas o de delitos de especial gravedad.

55 VIDINO, L et BRANDON J. (2012). Countering Radicalization in Europe. The International Centre for the Study of Radicalisation and Political Violence (ICSR), London, p. 70. Disponible en: http://icsr.info/wp-content/uploads/2012/12/ICSR-Report-Countering- Radicalization-in-Europe.pdf.

56 Comisión Europea, A Europe that protects: EU cities against radicalisation, 26 de febrero de 2019.

57 La interoperabilidad comenzará a implementarse con respecto al Sistema de Información Eurodac tras la aprobación de la $3^{\text {a }}$ fase del SECA. Si bien, ésta ya se encuentra regulada por los Reglamentos 817/2019 y 818/2019. Sobre el particular, véase el Reglamento (UE) 2019/817 del Parlamento Europeo y del Consejo de 20 de mayo relativo al establecimiento de un marco para la interoperabilidad de los sistemas de información de la UE en el ámbito de las fronteras y los visados y por el que se modifican los Reglamentos (CE) no 767/2008, (UE) 2016/399, (UE) 2017/2226, (UE) 2018/1240, (UE) 2018/1726 y (UE) 2018/1861 del Parlamento Europeo y del Consejo, y las Decisiones 2004/512/CE y 2008/633/JAI del Consejo y el Reglamento (UE) 2019/818 del Parlamento Europeo y del Consejo de 20 de mayo relativo al establecimiento de un marco para la interoperabilidad entre los sistemas de información de la UE en el ámbito de la cooperación policial y judicial, el asilo y la migración y por el que se modifican los Reglamentos (UE) 2018/1726, (UE) 2018/1862 y (UE) 2019/816.

(C) UNED. Revista de Derecho Politico

N. ${ }^{\circ}$ 107, enero-abril 2020, págs 303-335 


\subsection{La radicalización en línea como forma de lucha contra el terrorismo: un emergente conflicto constitucional asilo vs. seguridad.}

La prevención de la radicalización en Internet tiene su principal precedente en el año 2015, cuando la CE diseñó el innovador "Foro de Internet de la UE", que reunió a los gobiernos, Europol y a las mayores empresas de tecnología y redes sociales para garantizar que el contenido ilegal, incluida la propaganda terrorista, se eliminara a la mayor brevedad posible. ${ }^{58}$ Por su parte, el Consejo Europeo llevó a cabo el 23 de abril de 2015 una reunión extraordinaria sobre la lucha de la radicalización mediante la prevención del reclutamiento por medio de soportes cibernéticos en la que se evaluó, precisamente, la situación de la migración de emergencia en el Mar Mediterráneo, como parte de la orientación política otorgada a las agencias de la UE. Por primera vez, solicitó a Europol que ampliara sus actividades de vigilancia en Internet para contrarrestar la radicalización y el reclutamiento de terroristas que operaban frecuentemente en Internet. Fruto de ello, en 2016 fue creada la Unidad de Referencia en Internet (IRU - UE) para contribuir a la interrupción de las redes de tráfico ilícito de inmigrantes, detectando la imperante necesidad de eliminar cualquier contenido ilícito utilizado por los traficantes para atraer inmigrantes y refugiados. ${ }^{59} \mathrm{Un}$ asunto sobre el que se pronunció recientemente el TEDH en la Sentencia D y Otros c. Rumanía, de 14 de enero de 2020. ${ }^{60}$ En este caso, el Tribunal de Estrasburgo autorizó la devolución de un refugiado a Irak tras una condena en Rumanía por un delito de tráfico de migrantes, apreciando que no existían motivos fundados para considerar que este sujeto se enfrentaría a un peligro real de muerte o a malos tratos conforme a lo dispuesto en los arts. 2 y $3 \mathrm{CEDH}$.

La Directiva (UE) 2017/541 de lucha contra el terrorismo otorgó una primera respuesta a la prevención de la radicalización al reforzar el débil marco jurídico comunitario en este ámbito. ${ }^{61}$ Pese a todo, no regula toda una serie de cuestiones trascen-

58 Comisión Europea, EU Internet Forum: Bringing together governments, Europol and technology companies to counter terrorist content and hate speech online, Press release, 3 de diciembre de 2015.

59 La IRU - UE se inició en el contexto del creciente número de ataques y amenazas en Europa, donde se hizo patente que los recursos disponibles para investigar las comunicaciones basadas en Internet resultaban limitados por parte de los Estados miembros. Esta ampliación responde a un mejor coordinación y apoyo a las investigaciones nacionales. Europol (2016), EU Internet Referral Unit, Year One Report Highlights, European Police Office.

${ }^{60}$ Demanda $n^{\circ} 75953 / 16$. Sobre la vulneración directa o indirecta de los arts. 2 y 3 CEDH, remitimos a los últimos casos comunicados sobre la potencial vulneración del art. 3 CEDH: H.A. c. Grecia, presentada el 19 de noviembre 2019 (demanda n 59670/19), H.T. c. Grecia y Alemania, presentada el 1 de marzo de 2019 (demanda $n^{\circ}$ 13337/19), Poklikayew c. Polonia, presentada el 28 de diciembre de

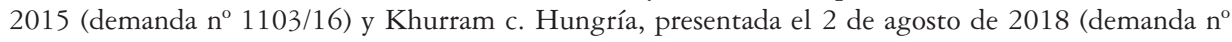
37967/18).

${ }^{61}$ En primer lugar, mediante la coordinación y el intercambio de información y experiencias sobre políticas nacionales de prevención (considerando 32), apoyo a los profesionales que entran en contacto con personas vulnerables a la radicalización (considerando 33). En segundo lugar, exigiendo el conocimiento de los delitos de terrorismo por parte de los Estados miembros independientemente del lugar 
dentales acerca de la radicalización en Internet, considerada una de las plataformas claves empleadas por mafias organizadas que trafican con migrantes y refugiados. Únicamente dispone en el art. 21.2 que los Estados miembros deben prever y eliminar cualquier tipo de provocación pública a la comisión de un delito de terrorismo en su territorio, adoptando medidas para bloquear el acceso a dicho contenido por parte de los usuarios de Internet. Ahora bien, ni establece las medidas concretas para solventar esta situación ni concreta mecanismos de coordinación efectiva entre los Estados miembros para frenar la propagación de contenido radical.

Paralelamente, y amén del alcance de esta Directiva en materia de prevención de la radicalización, la CE potenció algunos mecanismos para eliminar el contenido terrorista online en junio de $2017^{62}$, cuyo objeto era favorecer la mayor protección de los ciudadanos de la UE. Además de reforzarse las relaciones entre los Estados miembros ante un marco jurídico especialmente fragmentado y escasamente uniforme mediante fórmulas recíprocas de coordinación. ${ }^{63}$

Pese a todo, no se han acometido algunos de los grandes desafíos que sigue planteando Internet. Las actuaciones nacionales resultan escasamente coordinadas en la prevención, identificación y eliminación de contenido radical y extremista. De hecho, la CE informó que se habían difundido casi 700 nuevas piezas de propaganda oficial de Da'esh solo en enero de 2018 y la conocida Base de datos de Hashes, implementada por compañías del Foro de Internet de la UE, registraba más de 80.000 bashes de videos o imágenes terroristas solo durante $2016 .{ }^{64}$

Los comportamientos susceptibles de consideración radical no resultan fácilmente detectables por las autoridades nacionales y prestadores de servicios en la red. Una

en el que el grupo terrorista esté radicado o lleve a cabo sus actividades delictivas (art. 19.5). Ello teniendo en cuenta la necesidad de abordar un planteamiento global y preventivo a largo plazo sobre todo tipo de conductas de radicalización (incluidas en línea) y la captación para el terrorismo, por medio de eficaces medidas combinadas en materia de justicia penal con políticas de educación, inclusión social e integración. (considerando 31). Finalmente, exige de acuerdo con el art. 5 que los estados tipifiquen como delito la provocación pública para cometer un delito de terrorismo y diversos actos preparatorios (incluso en línea) cuya conducta preconice directa o indirectamente la apología de actos. Es decir, exige la tipificación de conductas de gravedad que, sin llegar a participar directamente en la comisión de ataques terroristas, pueden generar un elevado riesgo o propician su consecución. Directiva (UE) 2017/541 del Parlamento y del Consejo de 15 de marzo de 2017 relativa a la lucha contra el terrorismo y por la que se sustituye la Decisión marco 2002/475/JAI del Consejo y se modifica la Decisión 2005/671/JAI del Consejo, OJ L 88, 31/03/2017.

${ }^{62}$ Comisión Europea, 8. ${ }^{\circ}$ Informe de avance hacia una Unión de la Seguridad genuina y efectiva. $\operatorname{COM}(2017) 354$ final, junio de 2017.

${ }^{63}$ Por ejemplo, el Plan de acción anglo-francés publicado en 2017 incluía varias propuestas de acceso a contenido cifrado de información, así como la eliminación de material extremista entre ambos países. French-British Action Plan, 13 de junio de 2017. Disponible en: https://www.gov.uk/government/publications/french-british-action-plan-internet-security

${ }^{64}$ Comisión Europea, Security Union, A Europe that protects: Fighting Terrorism Online: Public-private sector cooperation as important as ever at the fourth EU Internet Forum, 5 de diciembre 2018.

(C) UNED. Revista de Derecho Político

N.o 107, enero-abril 2020, págs 303-335 
mejorada actuación conjunta a nivel comunitario que pretende solventarse, en buena medida, mediante la novedosa Propuesta de Reglamento sobre la prevención de la difusión de contenidos terroristas en línea. ${ }^{65}$ Esta perfeccionará la Directiva 2017/541 de lucha contra el terrorismo por medio de la regulación de las oportunas acciones nacionales que eviten contenido extremista terrorista en la red, ante el uso indebido de los servicios de alojamiento de datos. Su contenido pretende incrementar la salvaguarda la seguridad de los estados y reducir drásticamente, no solo la entrada de potenciales terroristas como solicitantes de asilo sino la radicalización de residentes comunitarios. ${ }^{66}$

En este sentido, su considerando $2^{\circ}$ alude a la necesidad de paralizar la utilización de los servicios de alojamiento de datos por parte de grupos terroristas y sus seguidores, acción clave que ha permitido difundir contenidos terroristas en línea, propagar mensajes de radicalización y reclutar a personas, así como facilitar y dirigir actividades terroristas. Si bien, sus disposiciones siguen resultando excesivamente amplias y propicias a la consecución de potenciales conflictos. Por ejemplo, el considerando 9 equipara el contenido terrorista con la mera expresión de puntos de vista radicales, polémicos o controvertidos en el debate público sobre cuestiones políticas sensibles. Una amplia consideración que, a juicio del Comité Meijers, resulta desproporcionada con la libertad de expresión e información ${ }^{67}$ y que parece solventarse, a priori, en virtud del art. 6, que establece estrictos criterios de proporcionalidad entre el riesgo y el grado de exposición a contenidos terroristas con el respeto de los derechos fundamentales de los usuarios y la libertad de expresión y de información en una sociedad abierta y democrática.

Esta propuesta regula todo un conjunto de medidas proactivas que pretenden compensar la propagación instantánea que producen este tipo de actuaciones radicales por toda la red y que genera un impacto adverso y de difícil ponderación en la salvaguarda de la seguridad de los Estados miembros. El art. 3 en relación con el art. 1 b) apunta a una mayor responsabilidad de los prestadores de servicios, que deberán evaluar, con carácter prioritario, los requerimientos de las autoridades competentes y eliminar información radical extremista. Además, la CE por su parte, propuso elimi-

${ }^{65}$ Consejo de la Unión Europea, Propuesta de Reglamento del Parlamento Europeo y del Consejo sobre la prevención de la difusión de contenidos terroristas en línea (15336/18), de 6 de diciembre de 2018.

66 Una prioridad que ha sido puesta de manifiesto por el Parlamento Europeo, Comisión de Libertades Civiles, Justicia y Asuntos de Interior, Informe sobre la propuesta de Reglamento del Parlamento Europeo y del Consejo para la prevención de la difusión de contenidos terroristas en línea (COM(2018)0640 - C8-0405/2018 - 2018/0331(COD)), 9 de abril de 2019.

${ }^{67}$ Meijers Committee, Standing Committee of Experts on International Immigration, Refugee and Criminal Law, Comments on the proposal for a Regulation on preventing the dissemination of terrorist content online, CM1904. (COM (2018) 640 final). 
nar el contenido extremista en Internet en un tiempo récord, tan solo 1 hora, ${ }^{68}$ una previsión que tipifica directamente el art. 4.2 de la mencionada propuesta.

Ahora bien, en el ámbito de la protección internacional, estas actuaciones no resultan ajenas a toda una serie de riesgos que impactan en dos ámbitos manifiestamente diversos:

1. La radicalización genera cuantiosos beneficios a mafias organizadas que trafican ilícitamente con migrantes. Estas poseen un gran conocimiento sobre puntos fronterizos críticos o botspots y son capaces de atraer a un gran número de migrantes que emprenden arriesgados viajes hacia países que garanticen condiciones idóneas de vida. Fruto de su vulnerabilidad, son fácilmente interceptados por traficantes expertos en la identificación de cualquier falla que permita penetrar con relativa facilidad en territorio comunitario. Además, se aprovechan de la escasez de personal y de condiciones materiales que, frecuentemente, disponen los campamentos de refugiados, diseñados y predispuestos a convertirse en "campos de cultivo" al arbitrio de los intereses de traficantes como así alude Loescher y Milner. ${ }^{69}$ Por su parte, Hathaway alerta que las políticas nacionales hacia refugiados fomentan un "purgatorio en campamentos y barrios marginales urbanos" ${ }^{70}$

Sobre este asunto, la Recomendación del Consejo de 22 de mayo de 2018 aborda parcialmente esta problemática, al promover políticas de inclusión como elemento disuasorio de la radicalización. ${ }^{71}$ Igualmente, la Red de Concienciación sobre Radicalización (RAN) está llevando a cabo en la actualidad numerosos esfuerzos en este ámbito, reuniendo a profesionales de todos los Estados miembros para desarrollar mejores prácticas que proporcionen las habilidades requeridas de forma que pueda afrontarse el extremismo violento procedentes de refugiados y migrantes. ${ }^{72}$ Este orga-

${ }^{68}$ Comisión Europea, A Europe that protects: Countering terrorist content online, 12 de septiembre de 2018.

${ }^{69}$ LOESCHER, G. et MILNER, J. (2014). "Protracted Refugee Situations and State and Regional Insecurity." Conflict, Security, and Development, vol. 4(1), p. 7.

${ }^{70}$ HATHAWAY J. C. (2019). “The Global Cop-Out on Refugees”, International Journal of Refugee Law, p. 11.

${ }_{71}$ Recomendación del Consejo de 22 de mayo de 2018 relativa a la promoción de los valores comunes, la educación inclusiva y la dimensión europea de la enseñanza.

72 En 2016, este organismo destacó en un evento temático titulado "La crisis de refugiados y migrantes: nuevos desafíos apremiantes para contrarrestar la política del Grupo de Trabajo contra el Extremismo Violento", que se estaban produciendo conductas susceptibles de consideración radical y el reclutamiento en los centros de refugiados y advirtió que un pequeño número de terroristas entre la gran cantidad de refugiados y migrantes se encontraban en estos centros. Ello constató que la crisis de los refugiados exacerbaba las tensiones y la polarización de la sociedad, produciendo efectos desventajosos como una mayor radicalización de los refugiados por parte del terrorismo yihadista extremista. Es más, el documento señalaba que los extremistas y terroristas intentaron polarizar deliberadamente la relación entre refugiados y Estados de acogida. El estudio refleja cómo el Daesh recoge en su revista online Dabiq la voluntad de "destruir la zona gris". De hecho, el Daesh ha producido docenas de videos sobre las crisis de refugiados y cuya temática comprende: 1 . Occidente no se preocupa por los refugiados. 2. Se considera que cualquier refugiado que huye a un área no musulmana ha cometido un gran pecado. 3. Debido

(C) UNED. Revista de Derecho Politico

N.o 107, enero-abril 2020, págs 303-335 
nismo incluyó una visita puntera en Suecia, en la que fueron aplicadas novedosas acciones de prevención del extremismo violento en el ámbito del asilo. ${ }^{73}$ El mencionado estudio llegó a la conclusión de la escasa interrelación entre ambas políticas y, pese a que aceptó que los refugiados poseían un mayor riesgo a ser radicalizados o explotados por reclutadores extremistas, también recalcó que coexistía un mayor riesgo de estigmatización por parte de este colectivo, cuya probabilidad de consideración como potenciales terroristas resultaba especialmente elevada.

En relación con el resto de Estados miembros, no se han producido destacados avances. En su defecto, la falta de mecanismos de prevención de estas conductas y las lagunas en este ámbito están dificultando gravemente los procedimientos nacionales de determinación del estatuto de protección internacional. Las autoridades deben elevar las cautelas y controles en el seno del procedimiento, exigiendo una compleja tarea de evaluación que establezca con rigor el grado de peligrosidad y si un solicitante puede ser merecedor del estatuto de protección internacional. Un conjunto de actuaciones que pueden resultar cruciales para la propia seguridad de los sujetos si la valoración de los comportamientos radicales reviste notoria entidad. Recuérdese que, en caso de serio riesgo la seguridad del Estado miembro de acogida, podría incluso aplicarse la cláusula de exclusión del art. 12.2 y 17 d) de la Directiva de reconocimiento. ${ }^{74}$

En la consecución de estos objetivos, Eurodac podría compensar esta excesiva rigidez aunque únicamente incluye información y datos de carácter personal, excluyendo la descripción de conductas o comportamientos susceptibles de consideración radical. Una carencia de tipicidad que viene compensada gracias a la acción de Europol que, a través de la UE-IRU, identifica contenido terrorista online en coordinación con los Estados miembros. Desde el año 2007, recoge anualmente en el Informe de situación y tendencias terroristas (TE-SAT) toda una serie de conductas europeas directa o indirectamente vinculadas con el terrorismo en Internet. El último Informe (2018) destaca que, aunque ya parecía que Internet desempeñaba un papel importante

a su pecado, cualquier musulmán que muera en el camino a Occidente será castigado por Dios. 4. Cualquiera que huya del capiphat se convertirá en un objetivo de Daesh. Véase Radicalisation Awareness Network (RAN), Centro de Excelencia, Ex Post Paper, The refugee and migrant crisis: new pressing challenges for CVE policies, 8 de mayo de 2016, p. 4.

73 La Red de Concienciación sobre Radicalización (RAN), Study visit on "PVE and CVE in and around asylum centres and within refugee communities", 13 y 14 de septiembre de 2018, pp. 2-3.

74 Sobre las cláusulas de exclusión, la Gran Sala TJUE en el caso H.F, de 2 de mayo de 2018, exige una evaluación individual previa a la adopción de la exclusión correspondiente por razones de seguridad nacional y orden público, desvirtuando la presunción que facultaba a excluir directamente de protección a un sujeto tras la comisión de los delitos tipificados como tal. Un avance trascendental en este ámbito que solventa la falta de determinación de actuaciones contrarias a la seguridad nacional, imponiendo una serie de límites que, en teoría, no comprometen la seguridad del Estado de acogida sino que elevan las garantías en la protección de este derecho. Véase STJUE (Gran Sala) H.F, de 2 de mayo de 2018 (Asuntos acumulados C-331/16 K y C-366/16). 
en la radicalización, la amenaza había aumentado de forma exponencial durante este último año. ${ }^{75}$

Por tanto, las políticas actuales potencian la inclusión de conductas sospechosas de radicalización en Internet por medio de un cruce de información sin precedentes. Una novedosa práctica sobre las que no existe parámetro de evaluación alguno y que pretende identificar exhaustivamente a todos y cada uno de los sujetos que entran a través de fronteras exteriores de la UE, especialmente, aquellos sobre los que existe información que revela su potencial conflicto con la seguridad de los Estados miembros. ${ }^{76}$ Esta intensa labor de prevención y detección deberá respetar, en todo caso, las más altas garantías en la protección efectiva de los solicitantes de protección internacional, traduciéndose en que, salvo manifiesta incompatibilidad con la seguridad nacional y/o comunitaria, la mera apreciación de comportamientos radicales no deberá excluir per se la concesión de estatuto de protección internacional. Su aplicación deberá efectuarse como último recurso, adoptando, en todo caso, todas las medidas de seguridad, económicas o sociales que permitan revertir este tipo de conductas o comportamientos.

2. La dificultad en la identificación de conductas susceptibles de radicalización excede de la evaluación efectuada en el seno del procedimiento protección internacional hacia cuestiones más complejas y vinculadas directamente con los residentes europeos. Durante 2017, la mayor parte de los ataques en la UE fueron principalmente cometidos por nacionales o residentes radicalizados en su país de residencia sin haber viajado al extranjero para unirse a un grupo terrorista. ${ }^{77}$ En marzo de 2018, la CE también constataba que la mayoría de los sospechosos de terrorismo involucrados en ataques recientes en Europa nacieron y/o se criaron en Estados miembros y se radicalizaron, precisamente, en los países de residencia. ${ }^{78}$

Finalizando, estos datos evidencian que la prevención de la radicalización requiere de contundentes esfuerzos coordinados por parte de las instituciones nacionales y comunitarias que se extiende más allá del procedimiento de determinación del estatuto de protección internacional hacia una serie de políticas coherentes no únicamente orientadas hacia la detección de comportamientos considerados radicales, sino que

${ }^{75}$ Europol (2018). European Union Terrorism Situation and Trend Report (TE-SAT), La Haya, p. 4.

76 Advierte la CE que, ningún sujeto cruzará las fronteras de la UE de forma inadvertida pues todas las bases de datos relevantes en material de seguridad se encuentran ya cruzadas. Comisión Europea, Security Union, A Europe that protects: 15 out of 22 Security Union legislative initiatives agreed so far, 20 de marzo de 2019.

77 Este informe destacaba la amenaza emergente de las conductas de radicalización cuya visión general desde 2006 reflejaba notorias transformaciones, por medio de suportes cibernéticos y ante la preferencia de llevar a cabo actos terroristas mediante artefactos explosivos improvisados. Sobre esta cuestión, subrayaba que los ataques yihadistas eran cometidos principalmente por terroristas locales, radicalizados en su país de residencia sin haber viajado para unirse a un grupo terrorista en el extranjero y que, frecuentemente, no tienen directos enlaces con el Estado Islámico o cualquier otra organización yihadista. Europol (2016), EU Terrorism Situation.., op. cit., p. 19.

${ }^{78}$ Comisión Europea, A Europe that protects: EU Mayors' Conference: "Building Urban Defences Against Terrorism, 8 de marzo de 2018.

(C) UNED. Revista de Derecho Politico

N.o 107, enero-abril 2020, págs 303-335 
favorezcan la inclusión social de grupos con mayores tasas de radicalización, entre los que se encuentran los sujetos con estatuto de refugiado o protección subsidiaria.

El Fondo de Seguridad Interna (ISF) deberá compensar la falta de seguridad y rigidez del procedimiento, apoyando a los Estados miembros de una manera más flexible y efectiva, a fin de que aborden eficientemente la lucha contra el terrorismo y la radicalización. Todo ello, potenciando el intercambio de información entre las autoridades policiales de la UE, intensificando las operaciones conjuntas transfronterizas y fortaleciendo las capacidades para combatir y prevenir la delincuencia en plena coherencia con el Fondo de Asilo y Migración. ${ }^{79}$

Por su parte, la detección temprana de estos comportamientos deberá asumirse por todo un conjunto de actores que intervienen directa o indirectamente en todo el proceso de integración de los refugiados, que deberán cooperar en la identificación de cualquier anomalía sensible desde su origen, tal y como ha llevado a cabo de forma pionera Dinamarca, que ha adoptado acciones que previenen y combaten el extremismo violento y la radicalización. Ello, gracias a la amplia colaboración entre varios actores de servicios sociales, los sistemas educativos y de salud, las autoridades policiales y los servicios de inteligencia y seguridad. ${ }^{80}$

\section{CONCLUSIONES}

Las distintas fases del SECA se han encontrado supeditadas a toda una serie de reiteradas y persistentes actuaciones nacionales tendentes a preservar y garantizar la seguridad ante complejos escenarios como los ataques terroristas o las crisis migratorias. Estas han producido un impacto adverso en la política del SECA contrariando — en buena medida — la aplicación uniforme de la política comunitaria en materia de asilo.

Los intereses nacionales han sido articulados como "elemento nuclear" de la política comunitaria de asilo, emplazando la seguridad nacional como eje vertebral del SECA, rebajando su sistema de garantías y propiciando un marco jurídico especialmente fragmentado. Esta dimensión nacional ha ocupado una posición de especial preeminencia en detrimento de la protección del derecho de asilo, es decir, el amplio margen de apreciación de los Estados miembros para determinar las conductas que comprometen su seguridad y la falta de categóricas respuestas en el plano comunitario a la capacidad de ofrecer soluciones comunes y coherentes a los problemas relacionados directa o indirectamente con el asilo y la inmigración ha aproximado excesivamente ambos intereses en juego.

${ }^{79}$ Comisión Europea, EU Budget for the Future, 13 de junio de 2018.

${ }^{80}$ Sobre esta cuestión, véase: Danish Institute for International Studies (2015). An Introduction to the Danish approach to countering and preventing extremism and radicalization; RAN Policy Paper, Developing a local prevent framework and guiding principles - Part 2, noviembre 2018. 
Los datos proporcionados en el presente artículo analizan la procedencia o nacionalidad de los solicitantes de protección internacional, el número de entradas por país y su directa traslación en los distintos ataques terroristas acaecidos entre 2014 a 2018. Su examen corrobora la disolución entre la concesión de estatuto de protección internacional y una mayor tasa de incidentes terroristas, incluso tras las graves crisis migratorias acaecidas en los últimos años en distintos Estados miembros como Italia, Grecia, Francia y España — con excepción de Alemania, donde aumentaron los incidentes terroristas durante la llamada crisis migratoria y de asilo comprendida entre 2015 y 2016 -

Pese a todo, las políticas nacionales priorizan su seguridad en detrimento del derecho a la protección internacional. Una interpretación extensiva que puede resultar incompatible con este derecho si se producen persistentes excepciones en la aplicación coherente del SECA, restringiendo generalizadamente su efectividad. Es más, este sistema se encuentra fuertemente influenciado por la incapacidad de asumir las grandes afluencias de migrantes en fronteras exteriores de la UE, favoreciendo la emergencia de muy diversos obstáculos a la garantía del derecho a la protección internacional.

Por fortuna, la nueva propuesta del SECA aborda la gestión de las solicitudes de protección internacional de una forma más eficaz —incluso ante circunstancias extraordinarias que pueden poner en serio riesgo la viabilidad de un Estado miembro-, a través de la transformación jurídica de la actual directiva de reconocimiento y procedimiento en reglamentos comunitarios, un renovado y "mejorado" Reglamento Dublín IV y el despliegue de novedosos y "perfeccionados" organismos europeos especializados en la gestión fronteriza.

Esta nueva propuesta de reforma del SECA acomete el concepto de seguridad mediante un progresivo traslado desde el seno de los Estados miembros hacia el ámbito comunitario, propiciando un nuevo enfoque conceptual de seguridad que debería resultar, más bien, integrado, complementario y yuxtapuesto al derecho a la protección internacional. Pese a todo, la propuesta no logrará resolver — con toda seguridad- estas cuestiones sensibles a nivel nacional puesto que no aborda algunos de los nuevos desafíos que seguirán comprometiendo la seguridad europea. Concretamente, nada regula acerca de la radicalización aplicable al ámbito de la protección internacional.

Se trata de un parámetro no cuantificado hasta la fecha que puede propiciar una peligrosa extensión del actual marco jurídico actual, perjudicando gravemente el régimen de garantías previsto en esta propuesta de reforma. En este sentido, puede advertirse una directa correlación entre la concesión de estatuto de asilo o protección subsidiaria y los problemas relativos al mantenimiento de la seguridad nacional. Los solicitantes de protección internacional presentan una mayor probabilidad a la radicalización en virtud de las distintas acciones que llevan a cabo militantes islamistas radicales, organizaciones terroristas o dedicadas a la trata de seres humanos próximos a éstos y que se agrava, en mayor medida, en el caso de los residentes europeos que 
ostentan el mencionado estatuto, tal y como así señala la CE y Europol. Un riesgo considerable teniendo en cuenta que poseen características personales que los hacen especialmente vulnerables como consecuencia de la persecución sufrida, a raíz de problemas de salud física o mental de notoria gravedad, por tratarse de menores no acompañados, etc.

Por lo que respecta al ámbito del SECA, conviene apuntar que, el actual refuerzo de las fronteras exteriores de la UE constituye una de las primeras y esenciales medidas en la lucha contra la radicalización. En el presente, la interoperabilidad de Eurodac con los distintos sistemas de información y, especialmente, el cruce de información con las bases de datos de Europol, permite cotejar un amplio catálogo de actuaciones susceptibles de consideración radical. Una "interconectividad" que resultará eficaz tras la entrada en vigor de la $3^{a}$ fase del SECA, fundamentalmente, tras el despliegue de los novedosos organismos especializados en asilo, gestión fronteriza y salvaguarda de la seguridad. Con ello, pretende otorgarse especial relevancia a la prevención e identificación anticipada de actuaciones que pueden comprometer la seguridad nacional.

Ahora bien, pese a que esta mayor disponibilidad de información aumentará posiblemente la detección de comportamientos y actitudes radicales, no deberá facultar a que las autoridades excluyan de protección internacional conductas que pueden afectar mínimamente la seguridad del Estado de acogida, sino que su apreciación requerirá de necesaria extraordinariedad, esto es, ante comportamientos radicales especialmente graves y manifiestamente incompatibles con sus intereses y mantenimiento de su seguridad nacional y orden público.

Por su parte, la Directiva 2017/541 de lucha contra el terrorismo ofrece una primera aproximación en la salvaguarda de la seguridad nacional en el ámbito de la radicalización de grupos vulnerables. Esta directiva prevé perfeccionarse con la novedosa Propuesta de Reglamento sobre la prevención de la difusión de contenidos terroristas en línea, con objeto de proporcionar medidas más eficientes que reduzcan los numerosos conflictos y riesgos actuales desde un enfoque mayormente comunitario. Especialmente, contempla contundentes respuestas para hacer frente a los contenidos terroristas en línea, incluso procediendo al cierre quasi automático de vínculos extremistas en Internet.

Con todo, estas medidas no resultan ajenas a potenciales efectos negativos para los solicitantes de protección internacional. La apuesta decidida por priorizar estas acciones sin precedentes que tienden a incrementar la seguridad online puede provocar verdaderos retrocesos tanto en la libertad de expresión e información como en la efectividad del derecho a la protección internacional. La predisposición por ampliar la inclusión de acciones susceptibles de radicalización puede generar una flagrante discriminación de este colectivo y un arma excesivamente discrecional en la aplicación de cláusulas de exclusión.

Por tanto, en aras de aumentar la prevención de ataques contra la seguridad y la efectividad de las medidas propensas a solventar la radicalización, éstas deberán adoptarse por Estados de acogida desde una fase inicial (tanto si el sujeto se encuentra sometido al 
procedimiento de determinación del oportuno estatuto como si ya ostenta estatuto de refugiado o protección subsidiaria) con la finalidad de prevenir posibles brechas en la seguridad. Incluso, como señala la CE, revertir este tipo de comportamientos en virtud de una labor asistencial crucial de Europol o los nuevos organismos europeos especializados en frontera (la GEFC, la futura AAUE o los equipos conjuntos de gestión de la migración de la UE). En todo caso, estas políticas requerirán una exhaustiva labor de adaptación a las necesidades específicas de cada Estado miembro y del propio perfil del solicitante (lugar de procedencia, sexo, motivo de persecución, edad, género, etc.).

En consecuencia, abordar los actuales y nuevos desafíos que enfrentan el derecho a la protección internacional con los problemas relativos a seguridad nacional implica proteger eficazmente la institución del asilo, reduciendo la errónea vinculación o nexo asilo y terrorismo y la estigmatización de este grupo vulnerable. El actual SECA exige nuevas y eficaces respuestas coordinadas en el ámbito comunitario que determinen las conductas especialmente graves que pueden resultar susceptibles de comprometer la seguridad, teniendo en cuenta que esta dimensión se encuentra cada vez más europeizada. Una acción que será adoptada tras la entrada en vigor de la inminente tercera fase del SECA aunque las medidas deberán efectuarse, en última instancia, a nivel nacional, respetando el fiel equilibrio entre la protección de los intereses nacionales y europeos y la efectividad del derecho a protección internacional.

Title:

National security and the exception in the Common European Asylum System.

\section{Summary:}

1. Introduction. 2. Problems related to security and its scope in the current European Common Asylum System (CEAS). 2.1. The impact of national security on the current CEAS. 2.2. Demystifying the current correlation between asylum and terrorism. 3. Security in the proposal for CEAS: keys to the new reform. 4. Radicalisation as an exception to the security assessment parameter in the CEAS. 4.1. Emerging challenges of radicalization and recruitment in the area of international protection. 4.2. Online radicalisation as a means of combating terrorism: an emergent conflict law asylum vs. security. 5. Conclusions.

(C) UNED. Revista de Derecho Político 


\section{Resumen:}

Desde los ataques terroristas del 11 de septiembre de 2001 hasta las recientes crisis de refugiados en la UE, las distintas fases del Sistema Europeo Común de Asilo (SECA) han propiciado continuas excepciones radicadas en seguridad, limitando gravemente los derechos de los solicitantes de protección internacional. Las políticas de seguridad nacionales en el ámbito del asilo se han ido conectando cada vez más al procedimiento de tramitación y, en su caso, de reconocimiento del estatuto de protección internacional. A priori, este nexo causal puede criminalizar a un colectivo especialmente vulnerable, desvirtuando el "mínimo denominador común" de la normativa comunitaria, lo que ha generado que el actual marco jurídico resulte especialmente fragmentado, incoherente e incluso, contrario al propio espíritu del SECA cuando la efectividad del mismo pivota en torno a la seguridad nacional.

La inminente reforma del SECA pretende proporcionar verdaderas mejoras en la relación seguridad nacional y protección internacional. Se prevé una progresiva traslación de los problemas competenciales relativos a la seguridad desde el seno de los Estados miembros hacia el ámbito comunitario. Pretenden abordarse estas cuestiones "por defecto", no solo gracias a un mayor perfeccionamiento del régimen competencial, sino también en virtud de una actuación mejorada de los nuevos organismos y agencias que aseguran un efectivo control de las fronteras exteriores de la UE. Ahora bien, esta no ofrece respuestas adecuadas a nuevos retos como la radicalización o reclutamiento de solicitantes de protección internacional y refugiados. Esto exige el diseño de un novedoso "marco proactivo o preventivo" que permita afrontar por parte de los Estados miembros imprevistas acciones terroristas o de delitos de especial gravedad.

\section{Abstract:}

Since the terrorist attacks of the 11th of September 2001 until the recent refugee crisis in the EU, some exceptions for security purposes have simply been provided in the different phases of the Common European Asylum System (CEAS). These modifications seriously restrict the rights of the applicants for international protection. National security policies in the field of asylum have been gradually aligned to the procedure for the processing and recognition of international protection status. This causal link may criminalise this particularly vulnerable group a priori, undermining the lowest-common-denominator of Community legislation. Consequently, the current legal framework becomes too fragmented, incoherent and even contrary to the heart of the CEAS when its axis pivotes around the dimension of national security.

The forthcoming reform of the CEAS aims at providing real improvements in the interrelationship between national security and international protection. Competence problems related to security is expected to be progressively transferred from the Member States to the community 
level. It addresses all of these concerns "by default" not only through the greater improvement of the competence regime but also creating enhanced bodies and agencies to ensure the effective control of EU external borders. However, this proposal does not develop appropriate responses to new challenges such as the radicalisation or recruitment of applicants for international protection and refugees, which requires a novel "proactive framework" that enables Member States to deal with unforeseen terrorist actions or serious crimes.

Palabras clave:

SECA, protección internacional, seguridad nacional, terrorismo, radicalización.

Key words:

SECA, protección internacional, seguridad nacional, terrorismo, radicalización. 